\title{
A HISTORY OF SUPERALLOY METALLURGY \\ FOR SUPERALLOY METALLURGISTS
}

\author{
Chester T. Sims \\ General Electric Company \\ Schenectady, New York 12345
}

\begin{abstract}
Summary
Superalloys are utilized at a higher fraction of their actual melting point than any other class of broadly commercial metallurgical materials. Superalloys are the materials which have made much of our very-high-temperature engineering technology possible. They are the materials leading edge of jet engines.

This "history" is an attempt to tell their story. However, it is not intended to be simply a logical recording of the events that have transpired to create them, but is intended to be a technically and scientifically useful analysis through chronological treatment, based upon consideration of the development of their significant property factors, the human factors, and other external forces which have generated these unusual, and now essential, materials.
\end{abstract}




\section{Background}

Over his existence man has developed equipment to satisfy his needs. Hundreds of years ago it became apparent to him that to do useful work, efficiency was related to use of high temperatures, starting perhaps with the power of rising warm air (Figures 1 and 1a). This then led to thermodynamic considerations such as the Brayton cycle, a basic physical tenet holding that higher use temperatures (accompanied by lower heat rejection temperatures) create more efficient operation.

The Brayton concept was applied to rotating engines. Relatively advanced steam turbines began to appear in the $1800 \mathrm{~s}$; in 1904 a gas turbine was being used for industrial electric power generation in Europe. Inventive man was moving fast around the turn of the century; essentially in parallel, the concepts of turbine engine power, the gasoline engine, and flight were developing.

United States interest in gas turbines started around 1905. Before long it was perceived that as airplanes developed, turbosuperchargers would be needed (Figure 1b) to provide their internal combustion engines with pressurized air/fuel mixtures because of the lower air pressures at high altitudes. The work on superchargers developed among Sanford Moss, a Cornell professor; the General Electric Company in Schenectady, and the U.S. Army. This effort (on exhaust-driven supcrchargers) spurred a continuing improvement in alloys, which created the leading position in high-temperature metallurgy (see Figure 1).

Then a scientific and technological phenomenon of immense importance occurred. Advances in aerodynamic theory directly caused a radical change in the thinking of designers in England, Germany, and Italy. It was (a) realized that turbulent drag wasted two-thirds of the power applied to conventionally driven aircraft, (b) Prandtl's airfoil theory involving the lift concept was applied to axial compressors and turbines, and (c) it became understood that the supersonic forces at the ends of propellers would not allow airplanes to be driven much above 400 miles per hour. These three factors together led to a new technology paradigm, the concept of jet engine-powered aircraft. It was revolution, not evolution.

It was thrust into man's life with the 1937 flight of Hans von Ohain's turbine engine in Germany, and independently, the 1939 flight of Whittle's engine in Fngland. Key events are identified in Figure 2; some of the equipment is shown in Figures 2a and 2b.*

With this new technology it became apparent to the mechanical designers that even higher temperatures were essential, and that new materials were needed to do the job. From then until now, progress in jet propulsion, and for industrial gas turbines as well, has been a growing engineering technology of immense importance. It also has been inexorably dependent on high-temperature alloy capability.

Meanwhile, metallurgy was moving from the age of copper and iron into stronger corrosion-resistant alloys; in the 1910-1915 era austenitic stainless steel was "discovered" and developed. Important here is that the $\gamma$ (face-centered cubic) austenite field of stainless steel became the specific physical arena from which superalloys have developed, although at that time alloy development for turbosuperchargers was along conventional lines - the strengthening of ferritic steels.

\footnotetext{
* In the United States, Boeing's perceptive and brilliant inventor Vladimir Pavlecki valiantly attempted to secure support for a similar effort, but apparently Government ignorance and corporate selfishness prevented any viable developments. This was particularly unfortunate because the U.S. had the clear lead in materials capability.
} 


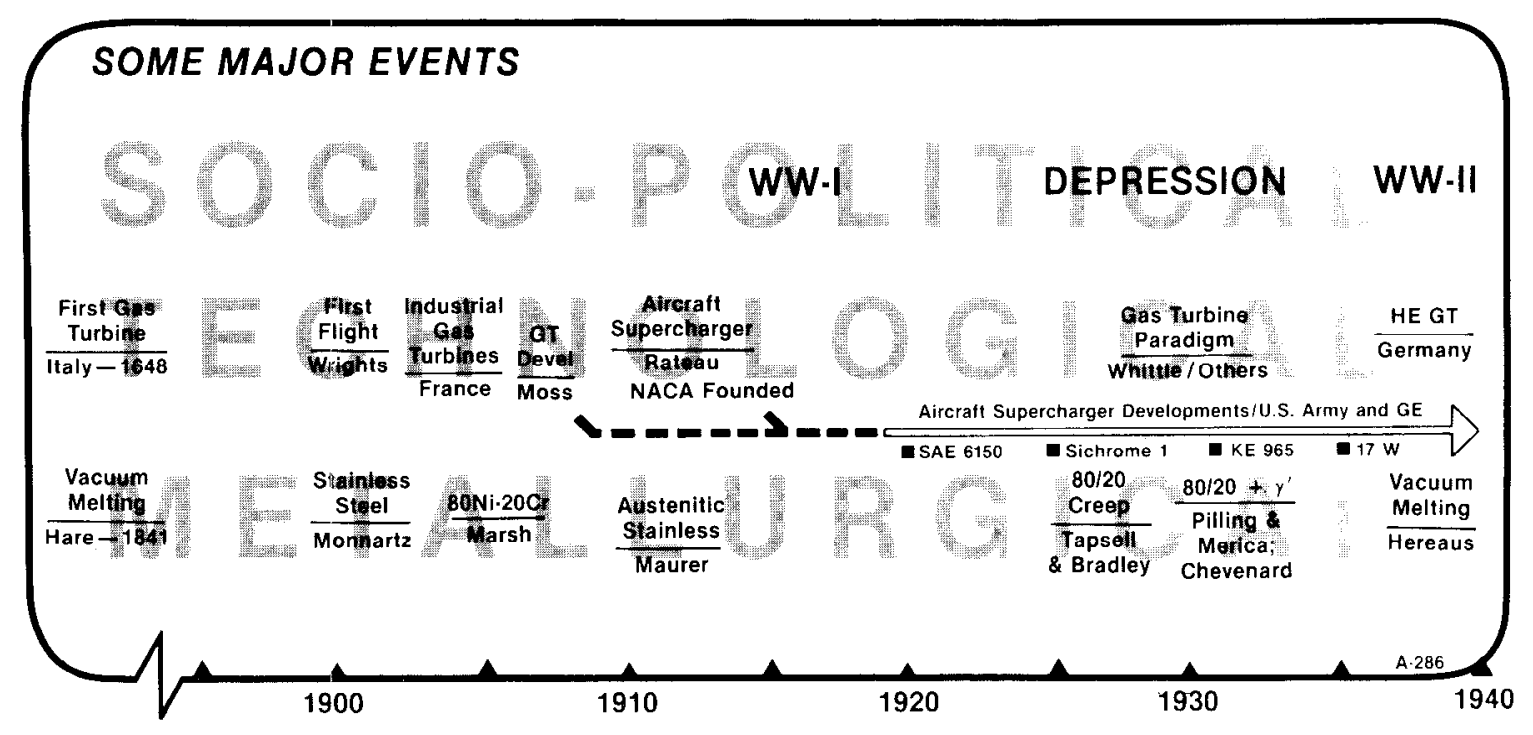

Figure 1. Historical data leading up to the invention and early application of superalloys.

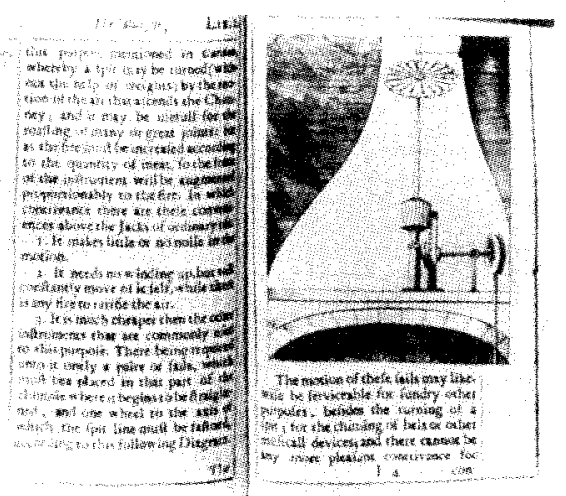

Figure 1a. The first gas turbine. Useful for household chores, after Bishop Gibbons" "Mathematical Majick," 1648.

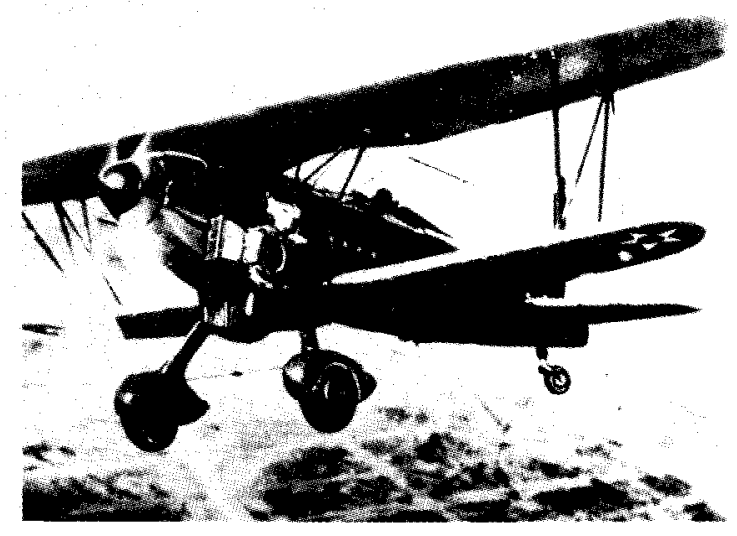

Figure 1b. Turbosupercharger on Curtis XP-23, 1932. A result of U.S. Army, Sanford Moss, and GE cooperation.

In 1929, virtuously simultaneously, Bedford and Pilling, and Merica, added small amounts of titanium and aluminum to the by then well-known " $80 / 20$ " nickel-chromium alloy. Significant creep strengthening occurred. Superalloys were "up" and virtually synchronous with the jet engine paradigm! Yet, it was not until nearly 1940 that Bradley and Taylor envisioned the existence of the tiny coherent phase that really did it $-\gamma^{\prime}$.

Despite inability to see such fine structures, the Edisonian experimenters of the 1930s in England, United States, and Germany all succeeded in creating strong alloys of nickel and iron base, containing chromium and $\gamma^{\prime}$, plus carbide-strengthened cobalt alloys. Some of the high points are shown in Figure 2.

The ongoing development of jet engine technology then continued to leverage development in these austenitic alloys, since it was realized that the potential of the jet engine was essentially unlimited. 
MORE MAJOR EVENTS


Figure 2. Events from the inception of superalloys to the present, set against the advent of superalloys of increasing capability.

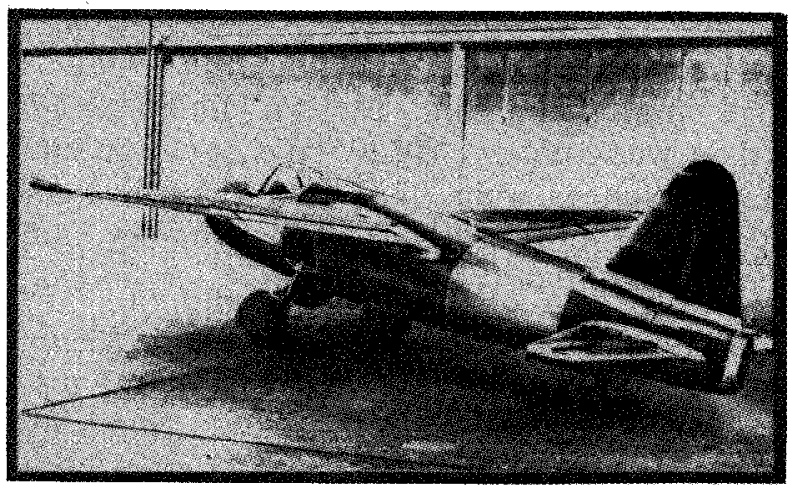

Figure 2a. First turbojet aircraft. German He-178 with Von Ohain HeS3B 1100-lb thrust engine, flown August 27, 1939.

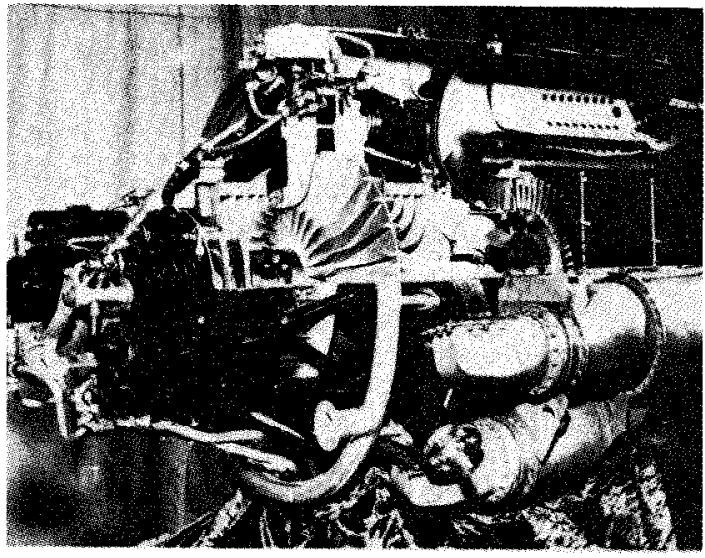

Figure 2b. Whittle engine. English W-1 as transferred to U.S. Air Force for subsequent development. Powered a Gloster Meteor in 1941. 
The 1940s showed rapid changes and developments driven by World War II. Shortly this was augmented by industrial "heavy duty" gas turbine needs, whose demands were not just for strength and high temperatures, but for reliability and realistic economic feasibility as well.

From there - the 1940s and World War II - the story of superalloys is one of further improvement and invention of new alloy compositions and new processes, driven first by military use of jet engines and then by industry, which needed industrial gas turbines. As the illustrations show, alloy development virtually exploded in the ' 50 s and ' 60 s, as did process development in the '70s and '80s.

While the gas turbine/jet engine machine and superalloy metals are inexorably intertwined, it is important here to note that superalloys have been developed for and utilized in a variety of other applications, such as high-temperature helium reactors, heat exchangers, furnaces, sour gas well equipment, and the like. However, the turbine/superalloy relationship is so coherent (with virtually zero mismatch) that this relatively short text will not attempt to separate out the other linkages.

It is the objective of this treatise to hold classic "historical" items to rather brief encapsulations, and attack instead the fascinating development of superalloys from the direction of specific technical and scientific advances (and setbacks) as represented by properties changes and inventive technical events, with a brief pause to discuss "The People and the Places" (Figure 3). Thus, in this superalloy story, each major technical factor is considered individually and also on a consistent chronological and mechanical property-advance basis. The "master" chart is Figure 2, and alloy examples by name are used from property to property to provide the common base. The intent is to provide superalloy users and developers with a broad and easily understood background of fact-related occurrences, augmented by a sense of the whole history.

\section{The People and the Places}

To provide initial personal and business perspective, Figure 3 identifies the people, industrial companies, and countries which have been prominent in superalloy development. The technical and patent literature make it clear that development of superalloys emanated principally from the United States, with significant work done in England and some in Germany in the early years. Presently, Japan and France are participating more and more strongly.

Using the invention of at least three commercially utilized alloys as the admission requirement, the names of those who have led the field are listed. The history of superalloys is the history of individuals - inventive, brilliant, fascinating. The most prominent are Clarence Bieber and Rudolph A. Thielemann, both recently honored by the Seven Springs Symposium.* However, team effort has also had its impact, as exemplified by the DanisiHocking-Lund-Woulds work at Martin Metals.

It is important to note that the people and the inventions were associated either with companies who made the alloys ("producers") or companies who used them ("engine manufacturers"). Superalloy invention and process invention cannot be done effectively by those not closely associated with a lurbine engine product.

\section{The Chemical Yeast}

Superalloy ownership and use rights patterns are based principally on their patented chemical compositions. Chemical composition is the core of the engineering specification defining the physical and legal statement of the solid matter. Figure 4 gives a very broad

* This listing is correct to the best of this author's knowledge, but he stands ready to be corrected upon presentation of firm evidence additive or contrary to that shown. 


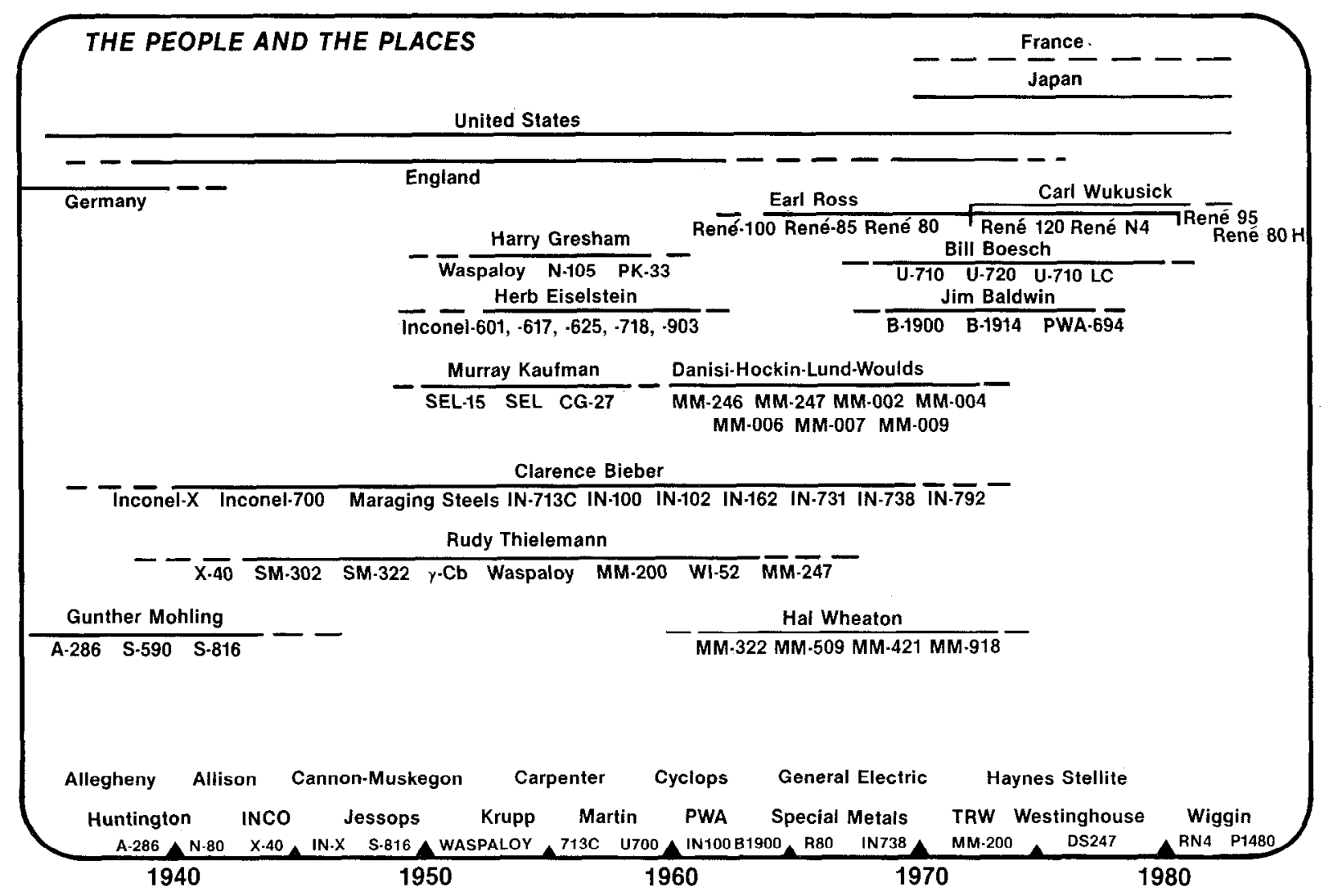

Figure 3. The countries, companies and people in the free world responsible for the core generation of superalloy development.

perspective of the trends in chemical composition with time. The figure is not to exact chemical content scale; composition can become very complex. The attempt here is to be very general and identify broad qualitative trends.

In the early years the alloys consisted only of an iron or nickel base with sufficient chromium present for oxidation resistance. Then, the small amounts of aluminum, titanium and/or columbium (first added in 1929) produced the coherent creep-resisting phase of $\gamma^{\prime}$, and sometimes the hidden enemy, $\eta$.

It can be seen that in the 1930s iron, obviously emanating as an alloy base from stainless steels, generally disappeared in favor of nickel and cobalt. Chromium, always a major alloying element for its contribution of oxidation resistance to the systems, was perceived as hobbling strength in the 1960s. However, reducing chromium led the unwary to the onset of "hot corrosion" problems, resulting in a more carefully considered use of that element. Of course, aluminum, titanium, and columbium, added to form $\gamma^{\prime}$, have never been present in large amounts. Added excessively, they became significant embrittling agents. Aluminum's role as the primary $\gamma^{\prime}$-former and as an important oxidation-resistant element makes it the most vital of these three.

In the late 1940 s it was found that refractory metal additions, led by molybdenum, created significant additional strengthening through solid solution and carbide effects. Tungsten, tantalum (and now rhenium) all now are utilized to this end.

Concurrently with these developments, carbon, of course, has always been present. Carbides act as point strengtheners and as sumps of carbon for solid state reactions. Carbides (and zirconium and boron) have salutory grain boundary effects. However, in the latest developments of single crystal alloys, these elements are not needed because there are no grain boundaries. 


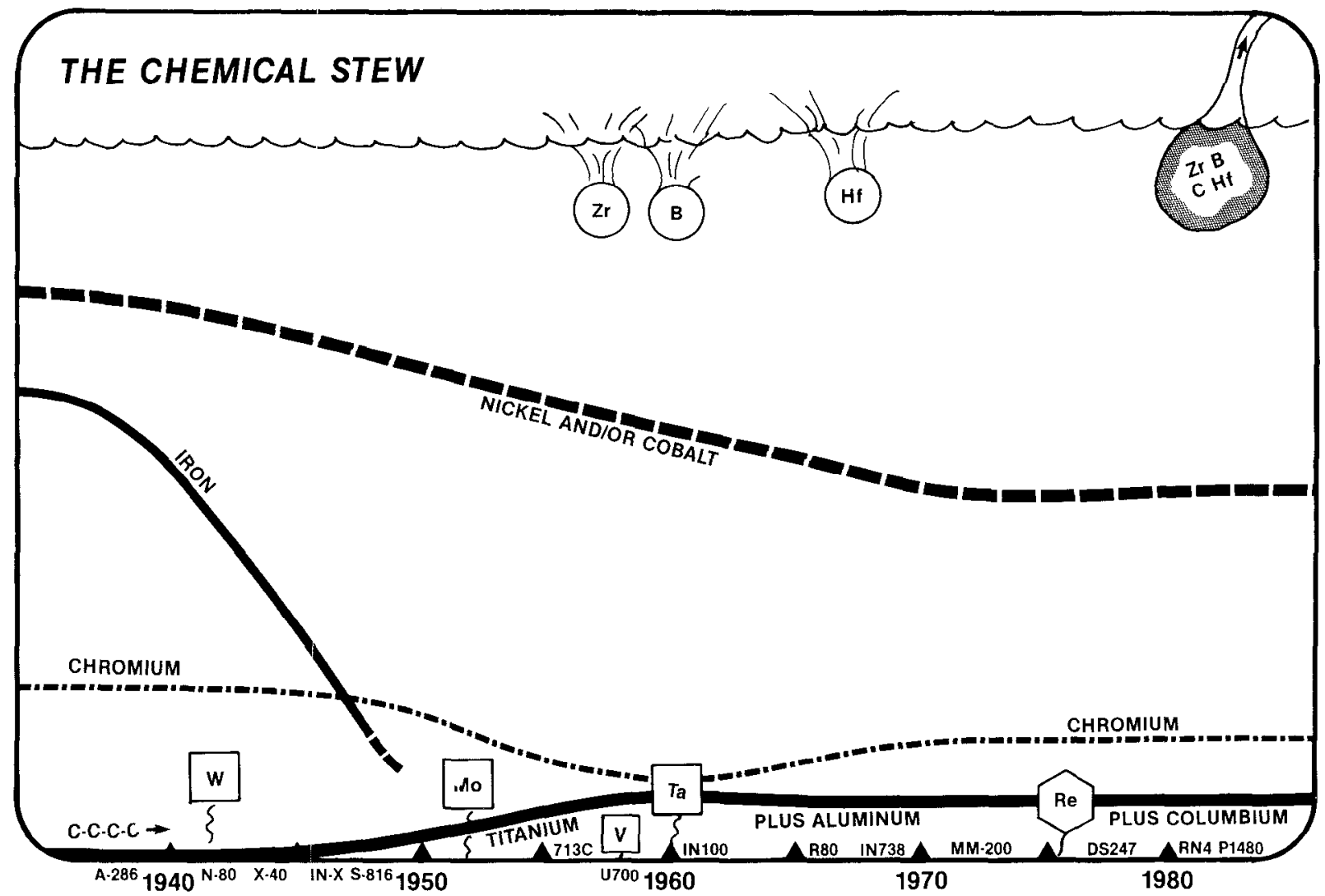

Figure 4. A qualitatively comparative view of trends in superalloy composition for representative superalloys.

Thus, superalloys can be considered to have traversed a period (1950-1970) when greater and greater amounts of differing elements were added for specific mechanical and chemical effects. Now, in the 1980s, some elements are being "removed," since advanced process developments create new structures not requiring them. Figure 4 a compares the composition of two alloys invented in the 1930s with several that are popular these fifty years later. However, it is important to understand that most of the early alloys are not extinct. Nimonic $80 \mathrm{~A}, \mathrm{~A}-286$, and X-40 are still mainstays in many critical components.

985

$$
\begin{array}{cccccccccccccc}
\mathrm{Fe} & \mathrm{Ni} & \mathrm{Co} & \mathrm{Cr} & \mathrm{Al} & \mathrm{Ti} & \mathrm{Ta} & \mathrm{Mo} & \mathrm{W} & \mathrm{H} \dagger & \mathrm{Zr} & \mathrm{C} & \text { Other } \\
65.5 & 26 & - & 15 & 0.2 & 2.0 & - & 1.3 & - & - & - & 0.05 & 0.015 \mathrm{~B} \\
13.0 & 43 & 22.0 & 18 & 0.2 & 2.1 & - & - & - & - & - & 0.05 & \\
& & & & & & & & & & & & \\
10 & 10 & 52.5 & 29 & - & - & - & - & 7.5 & - & - & 0.25 & \\
- & 66.5 & 4.6 & 8.0 & 5.6 & 0.9 & 5.8 & 0.6 & 7.9 & <.1 & <.01 & 0.005 & <10 \mathrm{ppm} \mathrm{S}, \mathrm{N}, \mathrm{O} \\
- & 70 & - & 15 & 4.5 & 2.5 & 2.0 & 2.0 & 4.0 & - & 0.15 & 0.05 & 1.1 \mathrm{Y}_{2} \mathrm{O}_{3} ; 0.01 \mathrm{~B} \\
18.5 & 52.5 & - & 19 & 0.5 & 0.9 & - & 3.0 & - & - & - & 0.04 & 5 \mathrm{Cb} ; 0.005 \mathrm{~B}
\end{array}
$$

Figure 4a. Chemical compositions. A comparison of early superalloys and those used $\mathbf{5 0}$ years later. 


\section{Significance}

Overall, Figure 4 gives us several messages. One is that austenitic superalloys are very complex; they usually contain many elements. Another is that a broad balance of alloy base $(\mathrm{Ni}+\mathrm{Co}$ at $-50 \%)$ and surface stability additions $(\mathrm{Cr}$ at $\sim 10-15 \%)$ was reached about three decades ago, and changes little. Changes in lesser elements are now the action pattern, connoting a subtle depth of understanding.

\section{The Phases of the Phases}

As in all other metallurgy, the alloy chemical composition defines the solid phases present. The phases in turn create a visible microstructure, discussed immediately following. Thus, these three - chemical composition, phase constitution, and microstructure define superalloys in the physical sense.

Figure 5 shows the most significant physical phases identified over the last fifty years which have created the unique strengthening in superalloys. Those phases which have been observed to be most deleterious to behavior also are identified. It should be remembered that these phases are chemically interactive with each other and the alloy matrix. At highest operating conditions, superalloy metal is a white-hot, dynamic entity of constantly changing solid state phases!

To the left we see, of course, that the alloy matrix always consists of the well-known austenitic FCC (Figure 5a). In the $1929-1930$ period, additions of aluminum and titanium to alloys in England, United States, and Germany created very slight amounts of $\gamma^{\prime}\left(\mathrm{Ni}_{3} \mathrm{Al}\right)$, a coherent "age-hardening" cubical strengthener, in the austenite. $\gamma$ ', for instance, was in both the English Nimonic 80 and the German Tinidur, or A-286. $\gamma^{\prime}$ now often composes up to $50 \%$ of contemporary nickel alloys, but cannot form in cobalt alloys. In the late 1950 s, Eiselstein's development of IN-718 revealed another unique phase, $\gamma^{\prime \prime} . \gamma^{\prime}$ is characterized by a simple FCC cubic structure; $\gamma^{\prime \prime}$ is two cubes stacked. When titanium was added alone, $\mathrm{Ni}_{3} \mathrm{Ti}$ phase occurred; however, it formed as plates and thus was deleterious to strength.

Concomitantly a variety of carbides were utilized and identified in both nickel and cobalt alloys. Of these, the $\mathrm{M}_{23} \mathrm{C}_{6}$ and $\mathrm{M}_{6} \mathrm{C}$ types are readily heat-treatable, while the slowly decomposing $\mathrm{MC}$ types are utilized as sumps for carbon release throughout life of the alloy. A classic solid-state reaction is

$$
M C+\gamma \rightarrow M_{23} C_{6}+\gamma^{\prime}
$$

In the 1960s big new things started to happen. ODS (oxide dispersion strengthening) was invented, and alloys with $\mathrm{ThO}_{2}$ and $\mathrm{Y}_{2} \mathrm{O}_{3}$ dispersions became commercial. Such oxide dispersions create creep strength to very high fractions of the alloy melting point. Then, with the advent of directional solidification, alloys developed by freezing based on phaseconstitutional relationships were created containing fibrous eutectics formed from $\mathrm{TaC}$, from $\mathrm{M}_{23} \mathrm{C}_{6}$, and from $\delta$-phase. These "eutectic" alloys are not yet commercially proven, but many predict their success.

Finally, from the phase view, a most recent activity is that wherein extremely rapid alloy solidification (such as is possible in making powder) can be used to cause suppression of phases. This gives the potential of bypassing undesirable phases. If such bypassing is stable, the commercial possibilities are obvious.

Some black clouds show up in our phase story. Of these, perhaps the most notorious blew up in the $50 \mathrm{~s}$ and $60 \mathrm{~s}$, when over-alloying by over-anxious metallurgists (of course driven along by their designer friends) caused formation of long brittle plates of $\sigma$ and $\mu$, as well as excessive amounts short rods of Laves phase. As alloys come under creep load in service, these plates initiate and promulgate fracture prior to realization of full alloy life, also discussed later in the section "Mechanical Behavior." Control of the alloy chemical 
THE PHASES OF THE PHASES
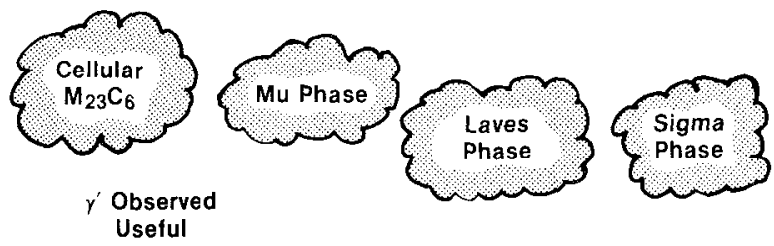

Fiber

Eutectic

$\gamma \cdot \gamma^{\prime} \cdot d$

Observed
Useful

G Phase

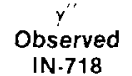

in Coatings

Fiber

Eutectic

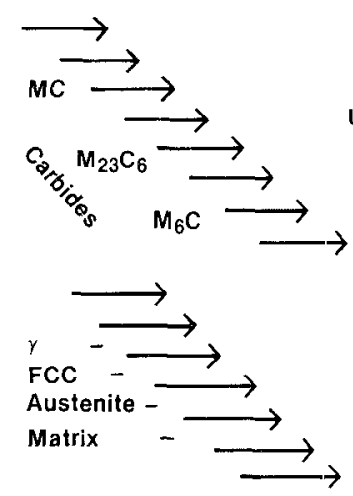

IN.718

$\mathrm{M}_{6} \mathrm{C}$

$r \cdot y^{\prime}$
Nodules

$\mathrm{Ni}-\mathrm{TaC}$

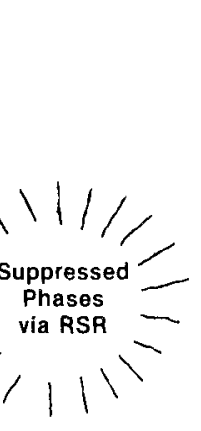

1940

$X-40$ IN.X $S .816$ WASPALOY 713

1950

1960

IN738 MM. 200

1970

1980

Figure 5. Discovery occurence of the major useful and the problem phases in superalloys.

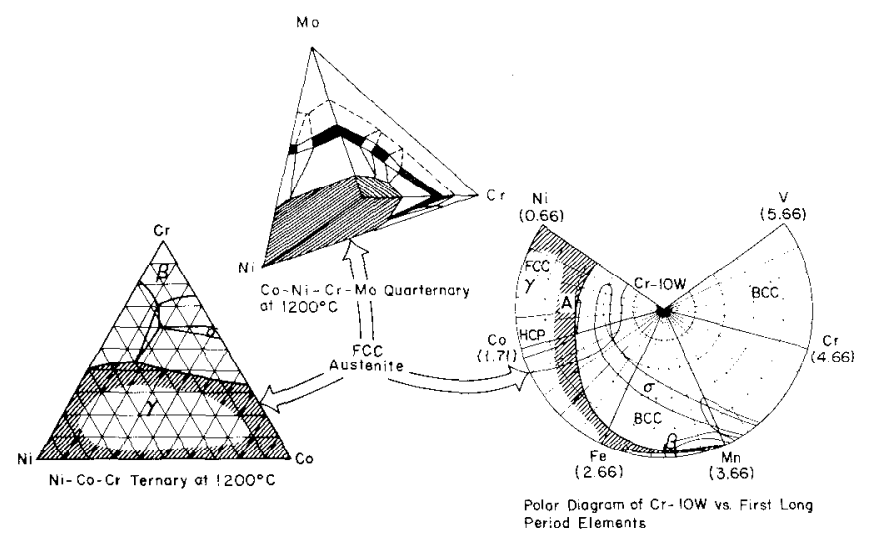

Figure 5a. Phase diagrams, showing the FCC $\gamma$ field.

Superalloy matrixes typically near "A."

composition to prevent such occurrence is essential, and led to the development of a computerized chemistry and phase-control tool called Phacomp. This appears to have been the first true commercial application of solid-state science through computerization. While Joe Bfpstlk had shown up with $\mu$ and Laves in the '30s, the full effect did not hit until the early '60s, with $\sigma$.

\section{Significance}

Knowledge, control, and perception of the phases occurring in superalloys and their generation and reactions is the centerpiece of alloy chemical development and alloy process development. Ultimately, attention to phase content in strengthening has resulted in the practice of "phase diagram metallurgy," as evidenced by eutectic alloys. 


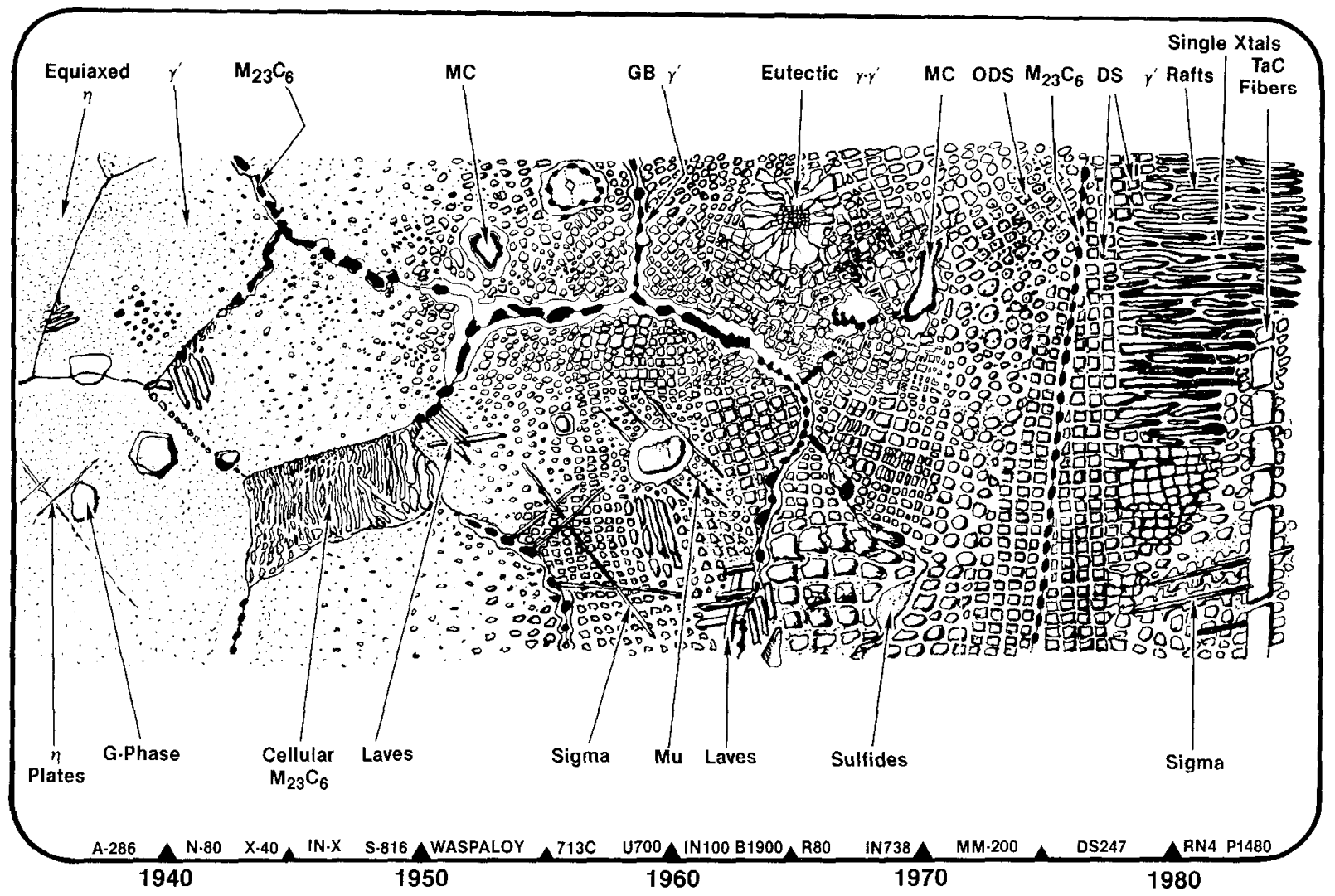

Figure 6. THE MICROSTRUCTURE. Panorama of the development of nickel superalloy microstructure, showing both useful and deleterious phases.

\section{The Microstructure}

As the chemical composition of superalloys creates the phase constitution, the phases in turn create the microstructure. It is unfortunate, but some of the earliest superalloy metallurgists may never have lived to see the tiny, beautiful, coherent precipitate phases of $\gamma^{\prime}$ that were making their alloys strong and useful, to say nothing of seeing the grain boundary details which enhanced strengthening and the prohlem phases such as $\eta$. It is thus to their eternal credit that outstanding progress was made strengthening superalloys during the $1930 \mathrm{~s}$ and ' $40 \mathrm{~s}$, using chemical analysis, light microscopy, and intuition. It was not until the advent of electron microscopy in the 1950s that we began truly to understand the visual relationship between the phases and the extreme complexity of superalloys.

Figure 6 is a panoramic at about $10,000 \mathrm{X}$ showing the 50-year development of nickel superalloy microstructure. The figure is intended to characterize the structures that made the alloys increasingly strong and ductile over the years. However, the lower part of the figure also includes some views of the "bad guys," - some of the problem-causing phases in the structure that have been found to cause brittleness and/or lowered strength.

It is obvious that from the early 1930s (Figure 6a, left) until the $1950 \mathrm{~s}$, the alloys created gradually were filled with more "structure"; this made them stronger and stronger. In the 1950s the "fill 'er up" era commenced in earnest. However, this also led to the significant problems created by the embrittling phases, such as $\sigma, \mu$. and Laves. Still, generation of more and more $\gamma^{\prime}$, both spherical and cubical, is apparent. The 1950 s also saw the creation of very complex grain boundaries, where carbides such as $\mathrm{M}_{23} \mathrm{C}_{6}$ lie engloved in $\gamma^{\prime}$, creating a dispersion-strengthened sheet bonding the grains together. By 1970 the effects of hafnium has been discovered and the $\gamma^{\prime}$-engloved carbide structure appeared unnecessary, since hafnium contorts the grain boundary to create strength and ductility in a more purely mechanical fashion. 

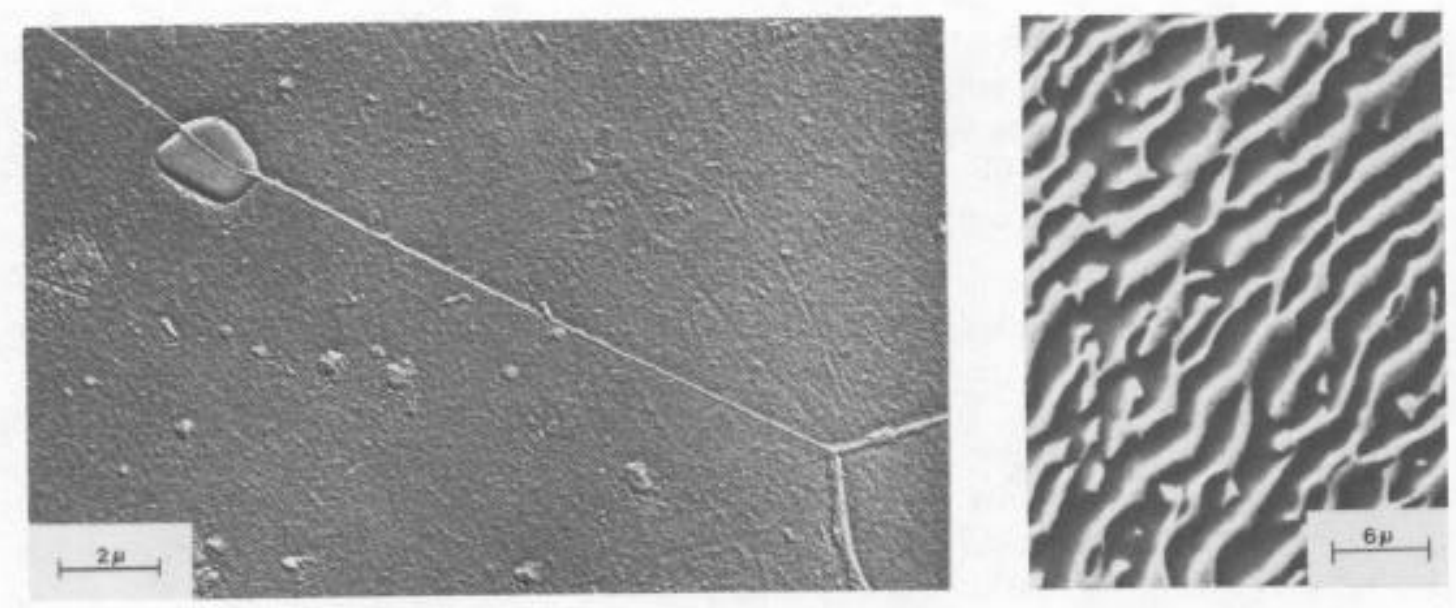

Figure 6a. Nickel alloys, then and now. Microstructures of wrought A-286 (left, about 1935), and cast single-crystal CM SX-3 (right, 1983). CM SX-3 courtesy Cannon Muskegon Corp.

Directional solidification processing creating aligned grain structures, aligned grain boundaries, and even alignable filaments (such as $\mathrm{TaC}$ ) - shown as they appeared in the $70 \mathrm{~s}$ and $80 \mathrm{~s}$. Finally, we see the aligned homogeneous single-crystal structures. Recently through heat treatment, transverse plates of $\gamma^{\prime}$ have been created in single crystals, which gives potential for still further strengthening (Figure 6a, right).

Figure 6b shows the structure of MM-509, a typical cobalt superalloy which appeared in the mid-60s. To generate creep strength, cobalt alloys depend primarily upon solid-solution strengthening, and interaction between carbide particles and alloy imperfections such as dislocations and stacking faults. The iron-base alloys of the 1930 s were similar.

\section{Significance}

Metallurgists have learned to utilize a series of strengthening effects which create a very complex interactive structure of finely divided phases in superalloys. Observation of these structures through use of tools such as the electron microscope has been enormously beneficial, allowing metallurgists to optimize the structures of the alloys with phases with a multitude of complimenting each other in their effects on structure strengthening and ductility.

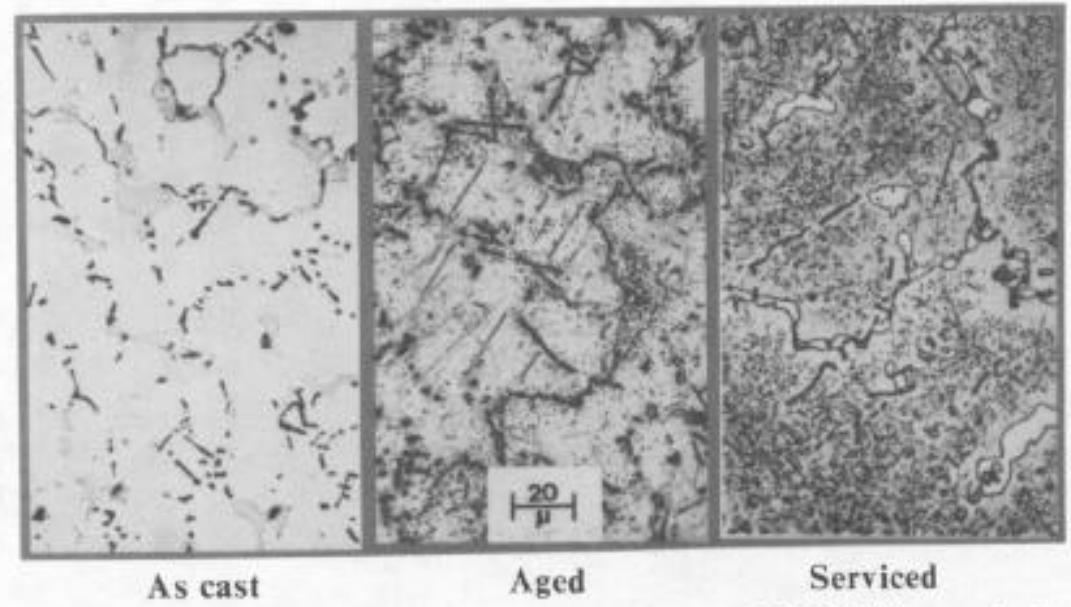

Figure 6b. Cobalt alloys. Microstructures of MM-509, serviced 732 hours at $2000{ }^{\circ} \mathrm{F}$. 


\section{Mechanical Behavior}

The primary raison d'etre of any superalloy is to demonstrate high strength (variously defined as high yield, creep, rupture, or fatigue strength) at high temperatures. A detailed discussion of progress in developing and optimizing these differing strength factors in superalloys would create a library. Accordingly, the major mechanical shortfall that has arisen for superalloys over the past 30 years is identified here and its effect is analyzed.

In the 1930s the strengthening of superalloys, whether iron-, cobalt-, or nickel-base, was just beginning. It soon became apparent that iron and cobalt alloys would be strengthened principally by solid solution and carbide strengthening, while nickel alloys also were the unique fortunate hosts to the coherent phase $\gamma^{\prime}$. As discussed above, by 1950 the leading supcralloy metallurgists became considerably versed in these techniques. Still, continuously subjected to incessant demands to create more and more "strength" for higher and higher temperatures, the metallurgists responded (Figure 4). They added refractory metals in increasing proportions for carbide and solution effects; they added aluminum and titanium to create more $\gamma^{\prime}$, and they also decreased chromium to increase the perceived allowable amount of $\gamma^{\prime}$. Strength indeed increased, as shown by the stress-rupture properties of successively issued alloys.

Interest concentrated in nickel-base alloys, since (because of $\gamma^{\prime}$ ) they could be made stronger and also are natively more oxidation-resistant. However, (Figure 7) the increase in strength was generally accompanied by a concomitant decrease in ductility. By the 1960s widely used alloys such as IN-100, René-100, and B-1900 were testing the limits of ductility. Metallurgists often joked that ductility measured in rupture or creep bar tests was more a function of a technician's capability to fit the fracture faces together than the actually recorded measurement. Still, the alloys grew stronger, hung together, and turbines performed.

However, inevitably, a host of mechanical problems began to develop, virtually all provoked in some part by low ductility. Metallurgists and designers battled these problems, each most concerned with some critical limiting property for their specific application. Optimizing composition and heat treatment, for instance, often had salutory effects.

By the middle ' 70 s it became apparent that the critical failure mechanism at high temperature was that of thermomechanical fatigue, a combination of ductility limitations in mechanical behavior and effects from surface attack, most succinctly expressed as a combination of low fracture toughness (Figure 7a). Since it was not acceptable to recover some ductility by retrogression to earlier, weaker nickel alloys (or to choose cobalt alloys which had not suffered this problem to the same degree) superalloy metallurgists turned to developments in processing.

The new developments in processing (such as directional solidification or powder metallurgy) then functioned to maintain or even improve strength properties while producing concomitant ductility. Processing is discussed subsequently.

\section{Significance}

As stronger alloys continued to be developed in the $1960 \mathrm{~s}$, a major property limitation was reached when low ductilities began to limit further alloy capabilities, and thus potentially limit advances in turbine performance. Thermomechanical fatigue became the current most broadly experienced failure mechanism. But as always before, ingenuity, expressed now principally by new developments in processing, kept the door open for more advance.

\section{The Surface Behavior}

Protection of superalloys from oxidation and corrosion from the aggressive atmosphere in which they serve is equally important with generation and utilization of their high 


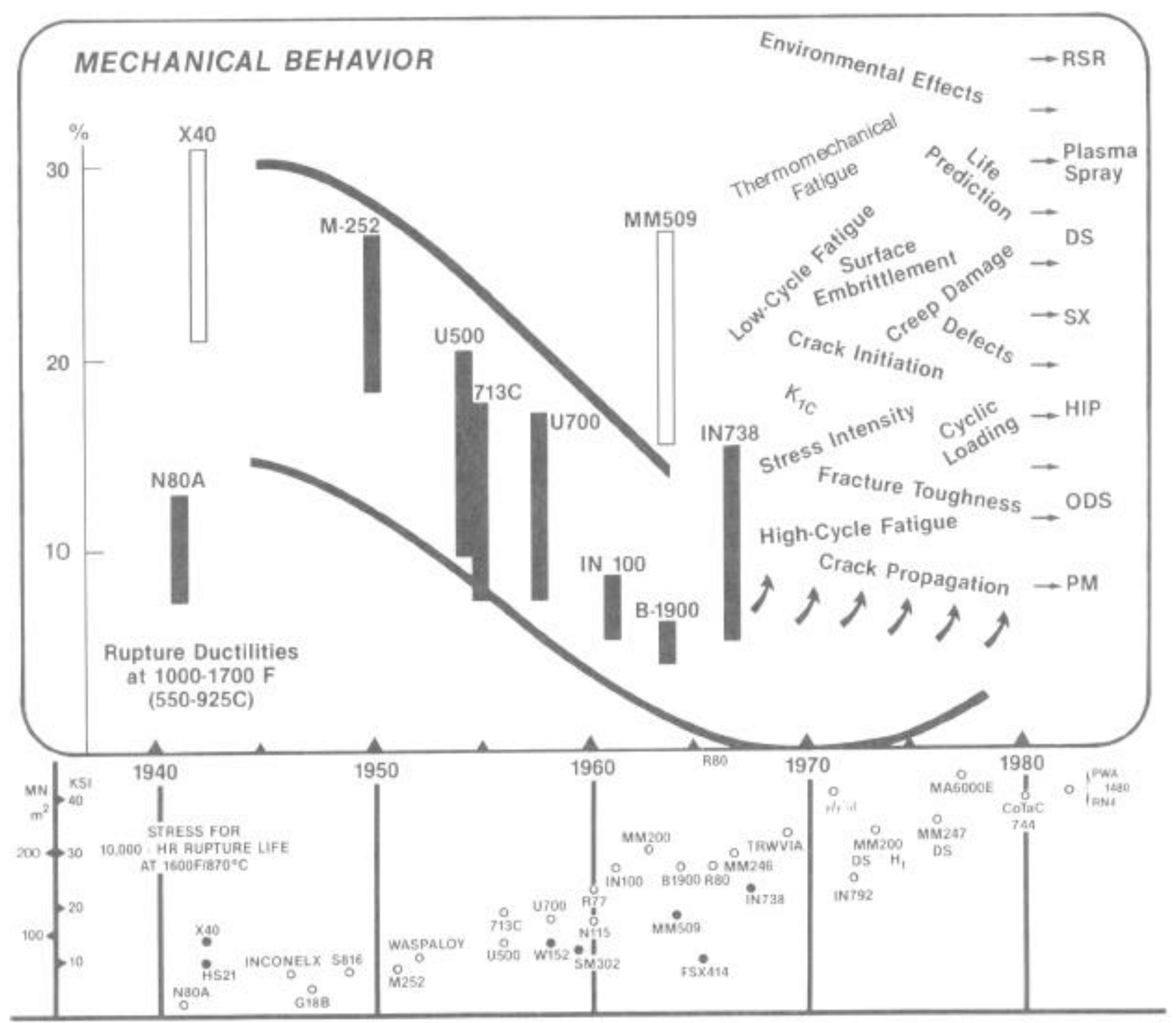

Figure 7. An illustration of the change in superalloy creep-rupture ductility with the issue of stronger superalloys.

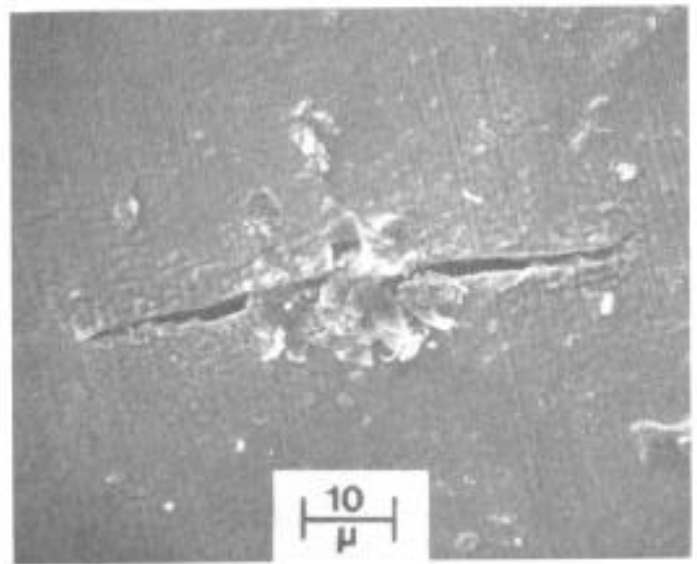

Figure 7a. Thermomechanical fatigue in IN-718, showing crack initiation at oxide polyp. After Coffin. 


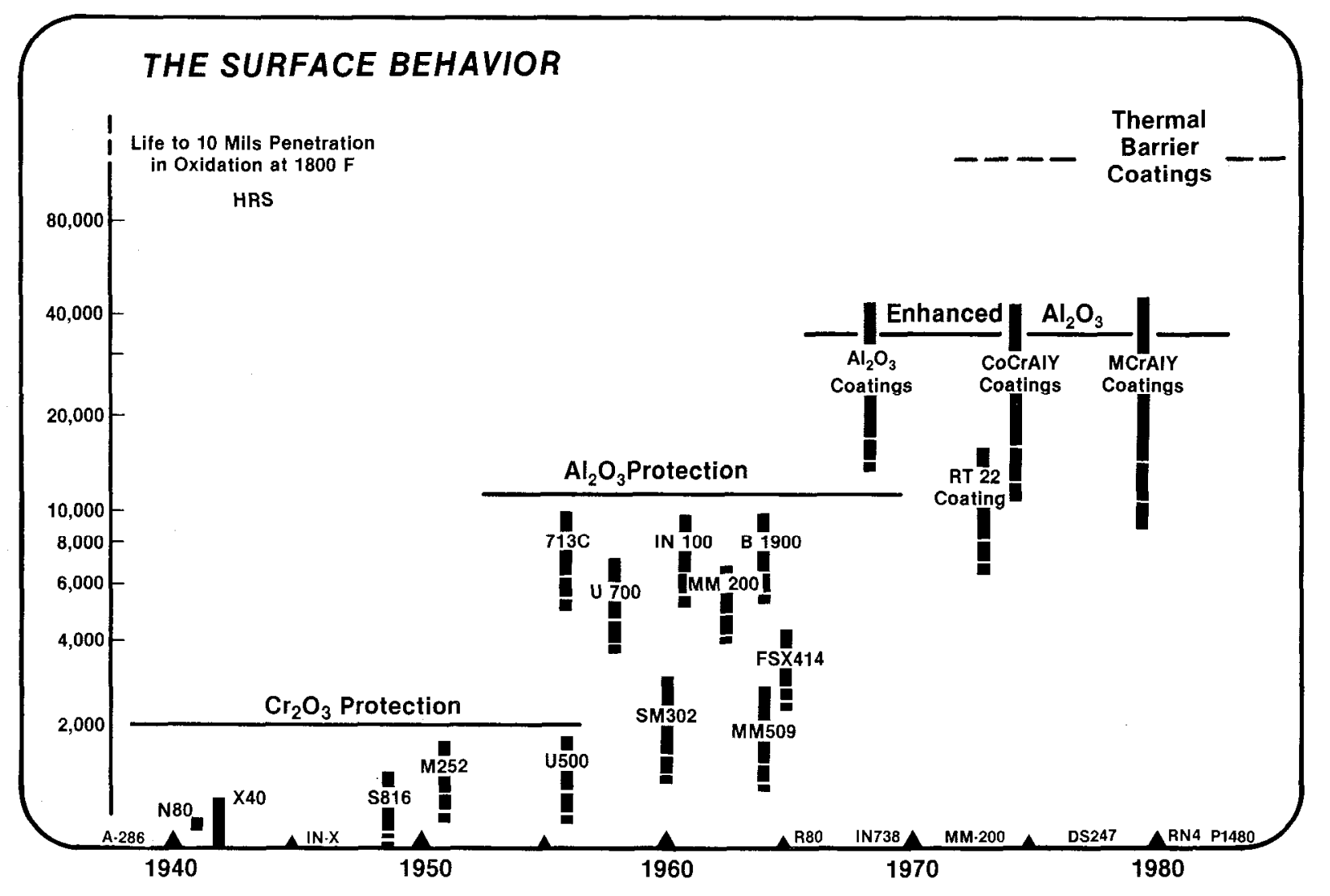

Figure 8. Advancing steps in the protection of superalloys against oxidation at high temperatures.

strength, although it attracts marginally less attention. A long view back seems to show that there have been three distinct eras related to surface protection, as illustrated by Figure 8 .

In the first decades, operation was at moderate temperatures (approximately $700{ }^{\circ} \mathrm{C}$, $\left.1500{ }^{\circ} \mathrm{F}\right)$, and the chromium level that came naturally on from stainless steels $(\sim 16$ to $25 \%$ ) was quite sufficient to do an acceptable protection job. Further, it protected the alloys against the then relatively dormant problems of hot corrosion. However, as temperatures rose, demand for better and better oxidation resistance generated. The potential of aluminum (which replaces $\mathrm{Cr}_{2} \mathrm{O}_{3}$ with $\mathrm{Al}_{2} \mathrm{O}_{3}$ ) was observed, studied, and its level in the alloys increased. Chromium was lowered from 18 to 15 to 12 and even to $10 \%$. Oxidation behavior improved. Aluminum, up to $5 \%$ or so, was doing the job.

However, particularly in the industrial sector, utilization of some of these alloys led to a problem called "hot corrosion"-enhanced oxidation resulting from sodium and sulphur in the fuel and gas stream. Then, ingestion of sea water spray into helicopter engines in the Viet Nam war wreaked havoc in low-chromium turbine blades, and a new "disaster" was born. The cssentiality of alloying to balance oxidation and corrosion resistance became a fundamental.

As temperatures continued to increase it became more clear that alloying to protect against oxidation and corrosion also often ran counter to alloying for improved mechanical properties. For instance, increasing chromium and lowering aluminum lowered $\gamma^{\prime}$ solution temperatures, and thus strength. Engineers turned to coating of superalloys to obtain required surface protection without significantly degrading mechanical properties of the underlying blade or bucket alloy (Figure 8a). This, in turn, led into the current period of "enhanced aluminum" where carefully balanced coating alloys (based on nickel, iron, or 
cobalt with chromium, aluminum, and other active elements) create extremely oxidationand/or corrosion-resistant protective skins. Generally, in today's technology, all superalloy load-bearing parts used at very high temperatures under dynamic conditions are coated.

Finally, the advent of "TBCs" (thermal barrier coatings) brings a new dimension. These thick, oxide-type coatings lower alloy surface temperature by reducing the heat flux, thereby decreasing surface attack. However, they can also increase hot corrosion by sponging up corrodants in their porous structures.

\section{Significance}

Perhaps the broad message is that while surface protection of superalloys from gas stream oxidation/corrosion may not always seem to carry the glamour of developing greater strength, it is just as essential, and the job has been well done. Coating of superalloys has been our first big step into generation of truly composite hot-stage turbine components.

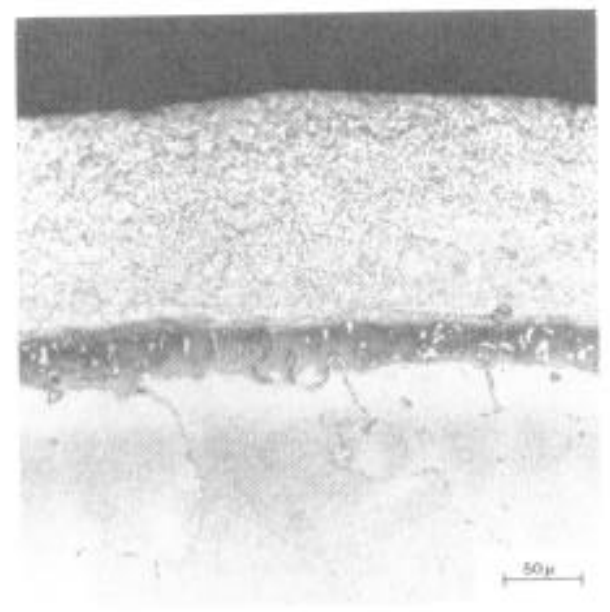

Figure 8a. Microstructure of a coated alloy.

\section{The Progress of Processing}

The big show in superalloys in recent years has been the the generation of revolutionary developments in processing. It is parallel in some ways to the great thrust in alloy development in the $1950 \mathrm{~s}$ and $60 \mathrm{~s}$. However, processing always has had a significant role in superalloy technology.

To this writer, it seems that "processing" has progressed through three principal stages. In the beginning, superalloys were used only in the wrought condition, made from forged stock. In the late 1930 s and 40 s the first question for a new superalloy application often was the query "cast versus wrought?" For a given high-stress application a ding-dong pattern frequently evolved. First, wrought alloys would appear superior, then, through slight design changes, a bit of processing advance, and a change in chemical composition, cast alloys would emerge as stronger and more economically viable. Then the forgers would go to work, the pattern would reverse, and the scene repeat.

The advent of vacuum melting around 1950 benefited both forged products and castings, and created a second major processing phase. Vacuum melting removed undesirable alloy impurities that had hamstrung alloy advances in the ' $30 \mathrm{~s}$ and ' $40 \mathrm{~s}$. It also permitted addition and control of vital reactive strengthening and oxidation-resistant elements; total alloy chemistry was improved immensely, and complex cast shapes were possible (Figure 9a). Vacuum melting was the most important process development made for superalloys in these first 30 years. In fact, the invention of vacuum meiting remains for many the most significant single development in superalloys. 


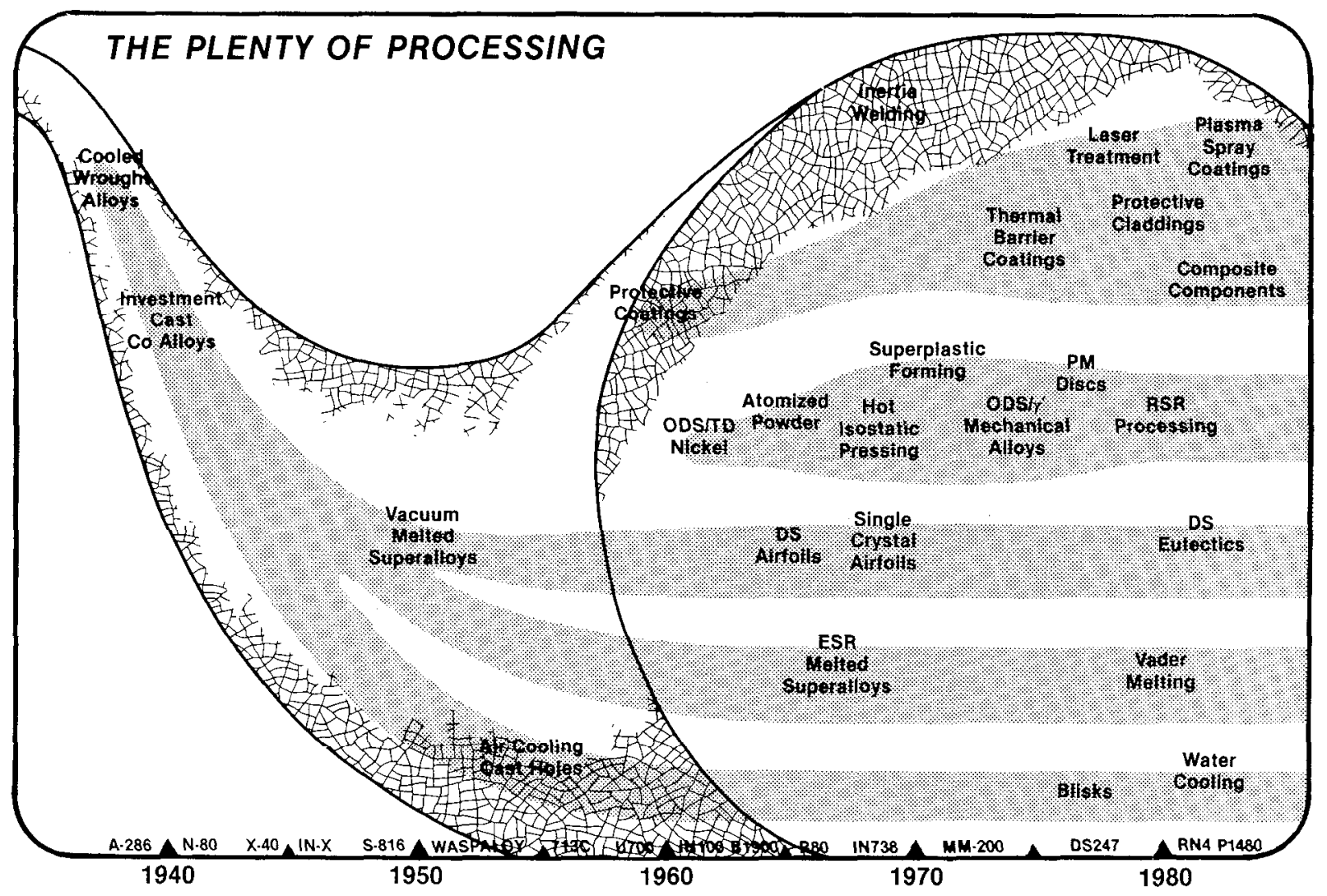

Figure 9. The explosion of process discoveries and developments in superalloys.

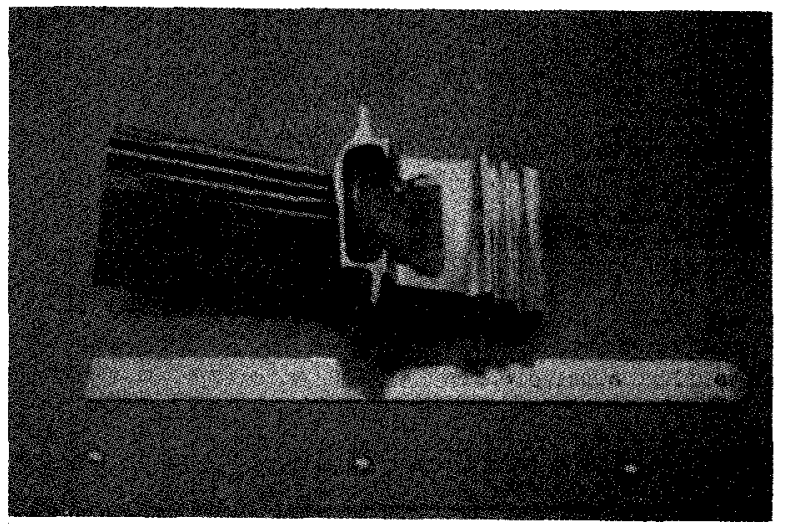

Figure 9a. Air-cooled complex internal structure of typical part made by the investment casting process.

During the 1950s, "processing" seemed to be taking a deep breath while the benefits of vacuum melting were absorbed. Then, in the $1960 \mathrm{~s}$ and $70 \mathrm{~s}$ a virtual explosion of new process developments occurred. By the mid-1970s this technological thrust certainly had surpassed "alloy development" as the prime forward drive to create better superalloys. The processing "horn of plenty" created is shown in Figure 9. Now, in the 1980s, alloy development is in a modest resurgence, but it is driven principally by the changing demands or increasing opportunities presented by the process developments started ten and twenty years ago. 
Figure 9 attempts to illustrate some of the avenues of activity as one step forward led to another. One of the major accomplishments has been the commercialization of the directional solidification process to produce columnar and single crystal airfoil components, as illustrated in Figure 9b; much of this work was done at Pratt and Whitney and TRW.

Approximately in parallel, oxide dispersion strengthening (ODS) came forth from Anders and Company at DuPont. As a product of powder metallurgy technology, ODS relates to very fine grain structures and superplastic properties. Now, combined with $\gamma^{\prime}$ strengthening, wrought ODS mechanical alloys generate usable creep-rupture strength to within $90 \%$ of melting temperatures.

\section{Significance}

Following years of developing improved properties in superalloys by alloying changes, a flood of process inventions took over the task of creating still further improved superalloys when advances by alloy development began to lag. At present, a dynamic interaction of both the new processing and alloy modification to enhance the advantages of the processing is occurring. However, in the overall sense we are clearly still in the "age of processing."

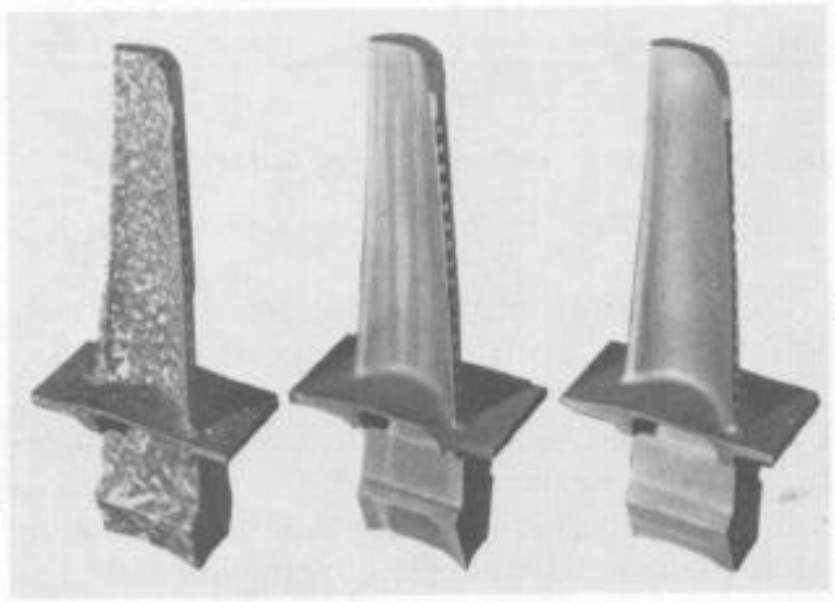

Figure 9b. Grain structure in (left to right) conventional equiaxed, directionally solidified, and single-crystal blade castings. Courtesy Howmet Corp.

\section{The Disasters}

Progress creating greater strength for higher temperatures in corrosive atmospheres has been outstanding for superalloys. However, as in other technologies, no such progress occurs without major setbacks and failures. Mastering the failures often provides a base for the next advance. Figure 10 summarizes these major setbacks, some of which have been discussed above. "Challenges" from competitive materials also are discussed here.

In the $1940 \mathrm{~s}$ it was found that cobalt-base alloys could suffer from over-alloying with carbon, and that uncontrolled age-hardening in service severely reduced serviceability. This was corrected by more care in alloying with carbon and the carbide-forming elements, and by control with improved heat treatments. 


\section{THE DISASTERS}

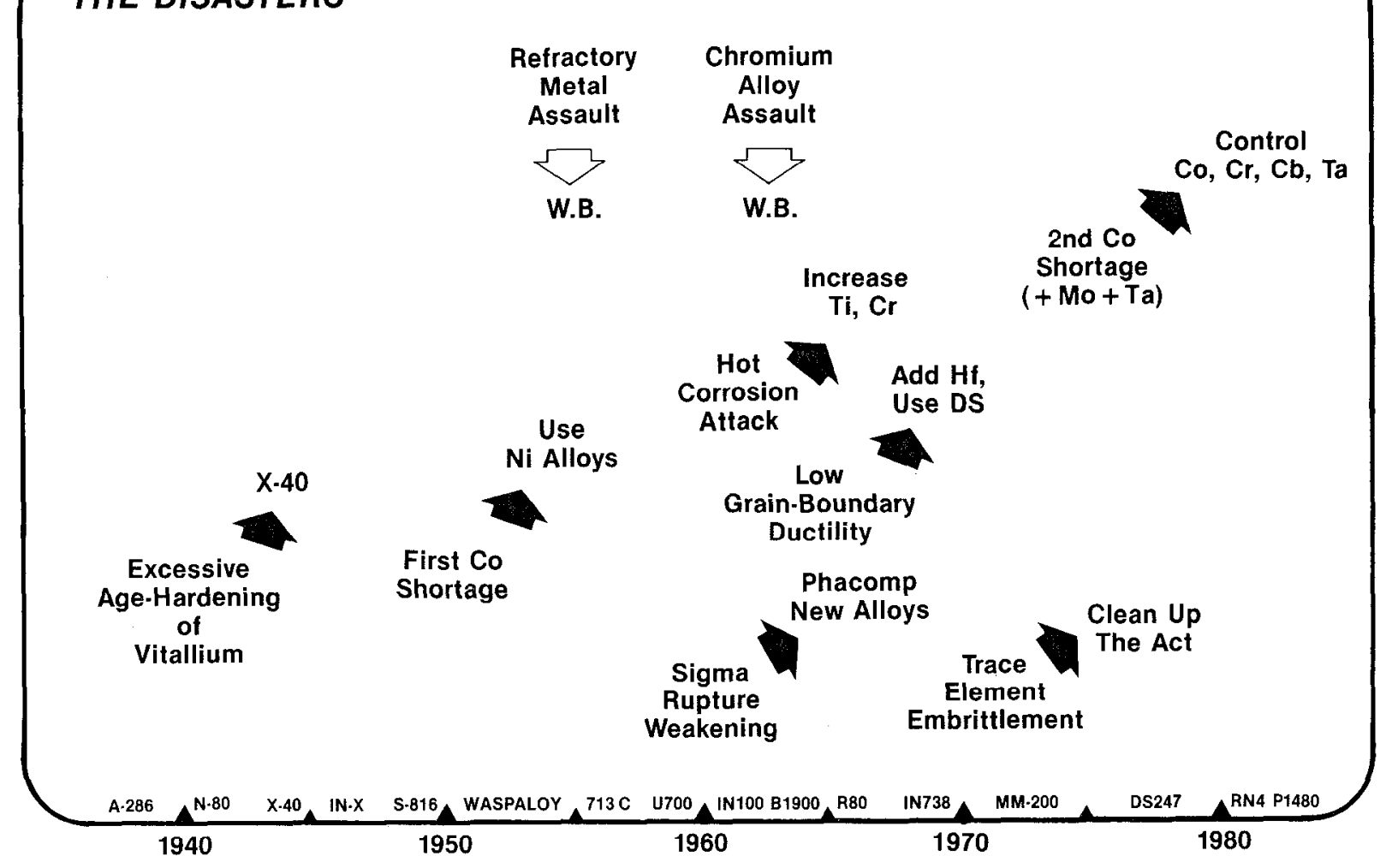

Figure 10. A chronological view of the major problems solved or bypassed in the development of superalloys.

In the 1950s a shortage of cobalt arose, causing a shift to nickel-base alloys. However, the world did not learn, and the same thing occurred in the late $1970 \mathrm{~s}$, due at least in part to the overseas source of cobalt in Africa. This time enormous costs were incurred; during the 1979-1980 shortage it is estimated that U.S. businessmen paid a premium of $\$ 0.5 \mathrm{~B}$ per year for cobalt before they could recover. Further, parallel shortages of other elements such as tantalum and molybdenum devcloped. Now, attention is being paid to reducing the need for "strategic" elements, and to scrap recycling, although the government claims to have stockpiles.

The intense alloy development pressure in the 1950 s so packed nickel systems with strengtheners that disaster came as the widespread service-incurred precipitation of platelike phases (Figure 10a) in the leading alloys, which resulted in premature alloy cracking and reduced creep and rupture performance. Chemical control from the computer tool Phacomp helped solve that problem. Phacomp was probably the first direct application of solid state electron theory to any alloy science.

A similar broad difficulty arose when the chromium reduction in nickel alloys to improve creep strength led to alloys susceptible to enhanced oxidation and hot corrosion (Figure 10a). This resulted in significantly shortened life for leading alloys in many industrial gas turbine applications as well as in aircraft engines subjected to a salt-containing atmosphere. A better chromium, aluminum, and titanium balance, together with coatings applied to hot parts, solved the problems.

The general "position" of superalloys has been challenged twice. First, in the 1950 s, an effort to develop refractory metal alloys for superalloy applications occurred. However, it was not possible to protect the refractory alloys acceptably from oxidation, and the effort 

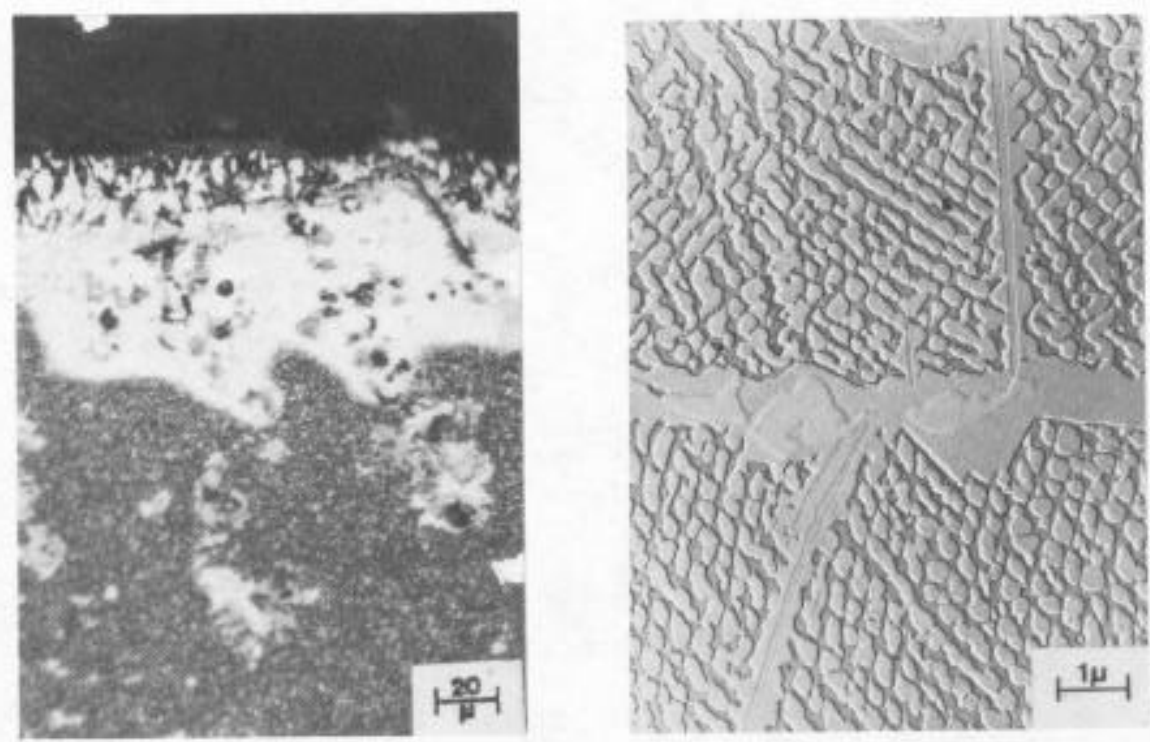

Figure 10a. Two big disasters. The onset of hot corrosion surface attack (left) and embrittling sigma phase (right).

died. It will probably recur. Similarly, at present an extremely heavily funded effort is being mounted to develop ceramics for turbine and other high-temperature service. The vigor in this drive has never been paralleled. However, after nearly 10 years of effort, there are yet no ceramic materials acceptable for commercial use; time will tell whether they can make it. Even if they do, superalloys will have a continued challenge in supporting structures.

\section{Significance}

Some severe metallurgical problems have arisen in superalloy technology. These "disasters" always have been solved by application of metallurgical and process developments which have led to still greater superalloy service capability. Two disasters in elemental supply from mine sources also have occurred. Will they occur again?

\section{Summary: The Major Eras}

As overview, Figure 11 gives this author's impression of the dominant engineering and metallurgical factors which appear to be the major inward- or outward-driving forces thrusting superalloy development.

Following superalloy conception from austenitic stainless steels, the demand of the concurrently developing jet engine obviously was the first driving force. In the engineering sense, gas turbine/jet engines are still the prime inward-forcing function.

Without question, however, Damara's invention of vacuum melting in the late $1940 \mathrm{~s}$ provided the process metallurgy leveraging for superalloy composition development by introducing a new era of alloy cleanliness and alloying element freedom. Vacuum melting alone produced cleaner, more ductile and reliable material for both forgings and castings, providing the opportunity for the great alloy development advances of the ' $50 \mathrm{~s}$ and ' $60 \mathrm{~s}$.

As the alloy development metallurgists reached their limits, running up against the problems of hard phase embrittlement, hot corrosion, and general ductility limits (Figures 7 and 9), the stage was set for an entrance of process developments. On they came, in a rush of an exciting and unusual nature. They were based in part on improved knowledge of the science of solids, as well as the use of innovative tools to do the processing itself, such as controlled heat removal to make single crystals, atomization to make powder alloys, and rapid cooling to create new structures. 


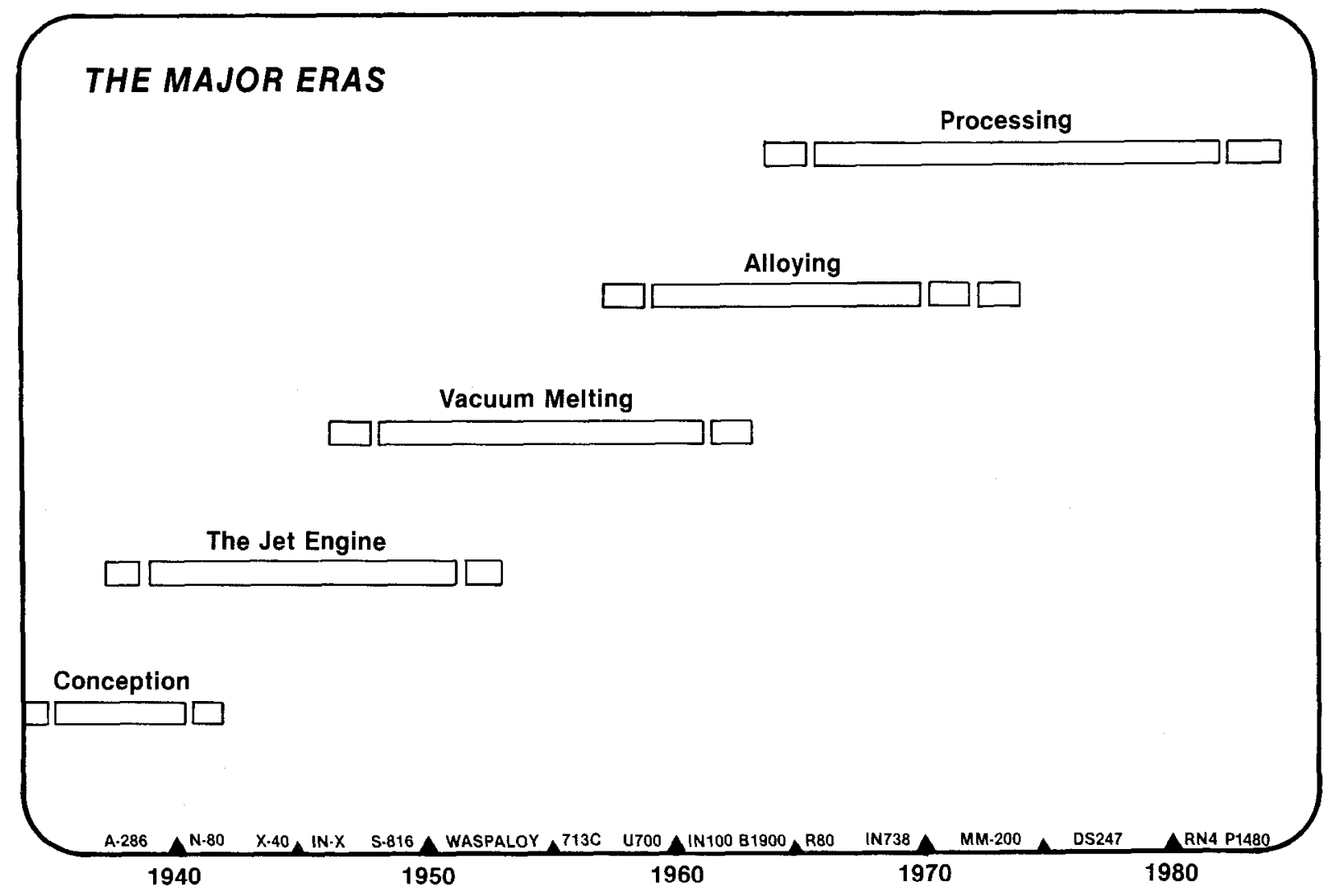

Figure 11. An overview of the dominant technology eras through the development of superalloys.

I'he pendulum never stops swinging, although its amplitude may decay. Now, we find the surge of new processing has reopened opportunities for alloying. Present alloying inventions, however, are clearly of a more delicate nature than previously, as exemplified by removal of grain-boundary strengtheners in single crystal alloys.

In total retrospect, a conclusion of inescapable logic burns out of this history. Superalloy metallurgists have invented and developed alloys more complex and used at a higher fraction of their melting point than any other comparable group! These accomplishments appear to have far surpassed that in any other equivalent metallurgical field in the last 50 years. However, the advance would not have been so total without the driving force emanating from the fortuitously parallel invention of the gas turbine jet engine. All together, this synergy has generated one of the great advances in engineering.

In prospect, perception of the next years is simple. The driving forces, the scientific base, and the people are in place to continue this advance. We all know it will happen, because we will make it happen.

\section{Acknow ledgments}

Many people have contributed their thoughts and advice to me recently, including spending time on some very helpful reviews. Particular thanks go to Carl Lund, Earl Ross, Bob Herchenroeder, Murray Kaufman, Adrian Beltran, Jack Wood, Jeff Metham, Bob Hendrickson, Fred Garry, Jack Westbrook, Gunnar Thornton, Bob Ashbrook, and Erik Falk. Also, over the years many other friends, too numerous to mention, have given their thoughts; more thanks to them, and apologies for not having maintained a list. 


\section{Bibliography}

1. W.T. Griffiths, "The Problem of High-Temperature Alloys for Gas Turbines" 739th Royal Aeronautical Society Lecture, London, Oct. 1947.

2. "Symposium on Effect of Temperature on Properties of Metals," proceedings of ASME and AST'M joint meeting, Chicago, June 1931.

3. N.P. Allen, "A Summary of the Development of Creep-Resisting Alloys," symposium on High Temperature Steels and Alloys for Gas Turbines, The Iron and Steel Institute, London, July 1952.

4. F.S. Badger, "High Temperature Alloys: 1900-1958," Journal of Metals (August 1958).

5. J.F. Hanieski, "The Gas Turbine," Technolngy and Culture, 14, (4) (1973) pp. 547-570.

6. Robert Schlaifer and S.D. Heron, "Development of Aircraft Engines and Fuels," lecture at Harvard University, Cambridge, Mass., Maxwell Reprint Co., Elmsford, NY 1950.

7. Lee Payne, "The Great Jet Engine Race-and How We Lost," Air Force Magazine (January 1982) pp. 57-64.

8. W. Betteridge and J. Heslop, The Nimonic Alloys, 2nd ed. Crane, Russak Company, Inc., New York, 1959.

9. J. Meetham, The Development of Gas Turbine Materials, Applied Science Publishers, London, 1981.

10. A. Williams, "The 20th Century," in A History of Technology, Parts I and II, McGrawHill, New York, 1965.

11. C.T. Sims, and W. Hagel, (ed.), The Superalloys, Wiley Interscience, New York, 1972. 